\title{
Analisis Pengaruh Brand Equity dan Perceived Product Quality terhadap Customer Value
}

\author{
Rita \\ Universitas Bina Nusantara \\ rita@binus.ac.id \\ Felix Felicio Kumayas \\ Universitas Bina Nusantara \\ felixfelicio21@gmail.com
}

\begin{abstract}
The purpose of this research is to examine the relationship and influence of Brand Equity, and Perceived Product Quality on Customer Value and have impact toward Purchase Intention of Mosquito Trap $\mathrm{Zz}$ One on company PT Global Indoraya Lestari. The respondent of this study is consumer that domiciled in Jakarta. This study uses Structural Equationg Model method to measure the relationship and influence between independent and dependent variables. In this study collected data uses questionnaire spread and achieve 100 respondent. The result of this study show the significance of relationship and influence of Brand Equity and Perceived Product Quality on Customer value toward Purchase Intention. But have one variables Perceived Product Quality not have significance individualy toward Purchase Intention on mosquito trap Zz One. FFK
\end{abstract}

Keywords Brand Equity, Perceived Product Quality, Customer Value, Purchase Intention

\section{PENDAHULUAN}

Industri Pest Control sudah berkembang dengan sangat pesat diiringi dengan pertumbuhan industri perhotelan, restoran, makanan, dan perumahan yang dilakukan secara besar-besaran dalam rangka memenuhi kebutuhan dan keinginan konsumen. Peningkatakan taraf ekonomi menyebabkan sebagaian besar masyarakat terjadinya pergeseran gaya hidup (life style) dan selera menuju tingkatan yang lebih tinggi maka Pest Control saat ini dianggap penting dan sangat dibutuhkan. Pest Control itu sendiri adalah suatu alat yang digunakan untuk membasmi hama-hama, hewan kecil, dan serangga di perkotaan seperti tikus, nyamuk, semut, kecoa dan serangga-serangga kecil lainnya. Negara Indonesia telah menunjukkan perkembangan yang positif dalam beberapa tahun terakhir, pertumbuhan penjualan Pest Control berjalan seiring dengan populasi penduduk yang terus meningkat. Penjualan produk Pest Control tumbuh secara kuat, selama 9 bulan pertama tahun ini membuat Bayer membidik pertumbuhan penjualan Pest Control sebanyak 30\% dibandingkan dengan tahun lalu. Nilai sebuah 
nama merek yang ditambahkan pada suatu produk merupakan gambaran dari ekuitas merek (Killa, 2008; Chang et al., 2008)

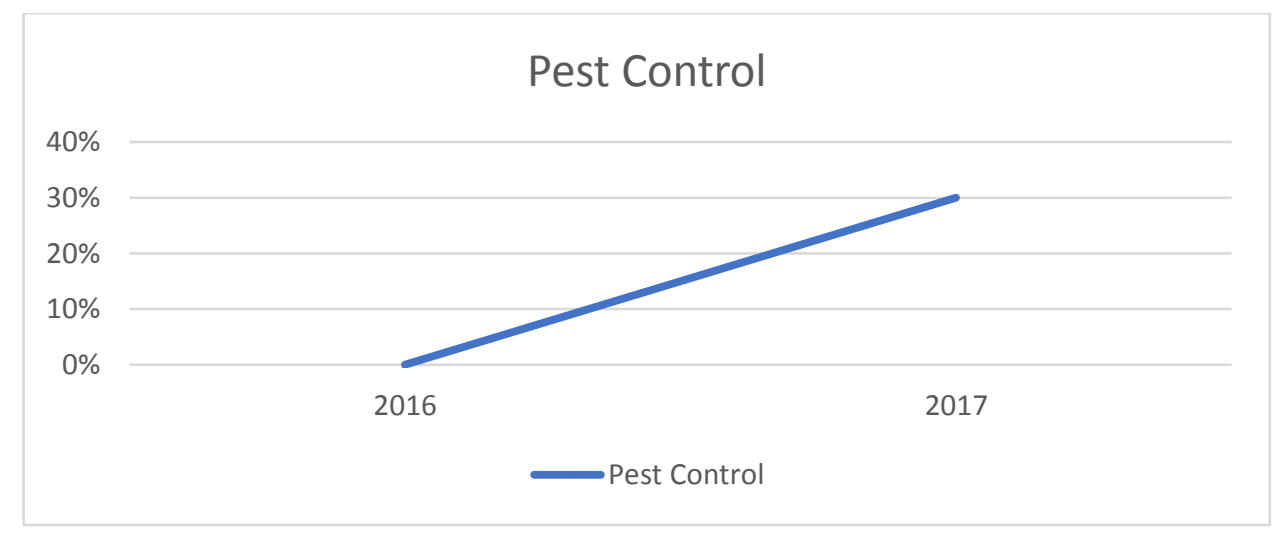

Gambar 1. Peningkatan Pest Control Bayer Indonesia Sumber : http://industri.bisnis.com (2017)

Oleh karena itu, banyak orang berupaya untuk menipiskan kemungkinan digigit nyamuk, berbagai cara dilakukan oleh manusia. Salah satu pengusaha yang memproduksi pembunuh nyamuk elektrik Andy Suryansah mengatakan dari hasil riset yang dilakukannya bahwa permintaan terhadap produk pencegah gigitan nyamuk tinggi karena gaya hidup orang yang diteliti dari 100 orang di Indonesia, hampir 51,31\% sangat konsumtif. Namun obat nyamuk bisa dibilang lahan para pemain pasar besar karena harganya yang murah. Namun tidak semua orang merasa kebutuhannya untuk terbebas dari gigitan nyamuk terpenuhi oleh obat nyamuk konvesional. Efek samping bahan kimia dari obat nyamuk yang menjadi alasan banyak orang untuk mencari alat pencegahan gigitan nyamuk lainnya. Karena melihat peluang yang cukup besar maka Andy memproduksi alat perangkap nyamuk saban bulan menghasilkan sekitar 300 - 350 unit. Untuk memasarkan hasil produksinya, Andy menggunakan jasa agen dalam sebulan produk yang terjual mencapai antara 250 unit - 300 unit yang dapat disimpulkan maka permintaan terhadap perangkap nyamuk sangat tinggi. Perilaku konsumen yang dipengaruhi oleh nilai pelanggan dan tingkat kepuasan pelanggan akan berdampak pula pada kepuasan merek yang berarti juga kepuasan pelanggan (Saragih, 2005).

Dalam hal membasmi nyamuk membuat warga meningkatkan kesiagaan dengan membeli produk anti nyamuk. Lonjakan penjualan dialami PT Sharp Electronic Indonesia. Perusahaan ini mengklaim kenaikan penjualan produk anti nyamuk bernama air purifier mosquito catcher. Yudha mengatakan adanya kenaikan penjualan air purifier mosquito 5\% - 10\%. Kenaikan penjualan produk anti nyamuk juga dilaporkan distributor produk perlengkapan rumah tangga seperti PT Ace Hardware Indonesia Tbk (ACES). Sebagai informasi ACES memiliki beragam produk electric insect killer yang bertujuan untuk membunuh serangga termasuk nyamuk. Nilai meningkat seiring dengan meningkatnya kualitas dan pelayanan, dan sebaliknya me- nurun seiring dengan menurunnya harga, walaupun faktor-faktor lain juga dapat me- mainkan peran penting dalam persepsi kita akan nilai (Kotler dan Keller, 2009) 


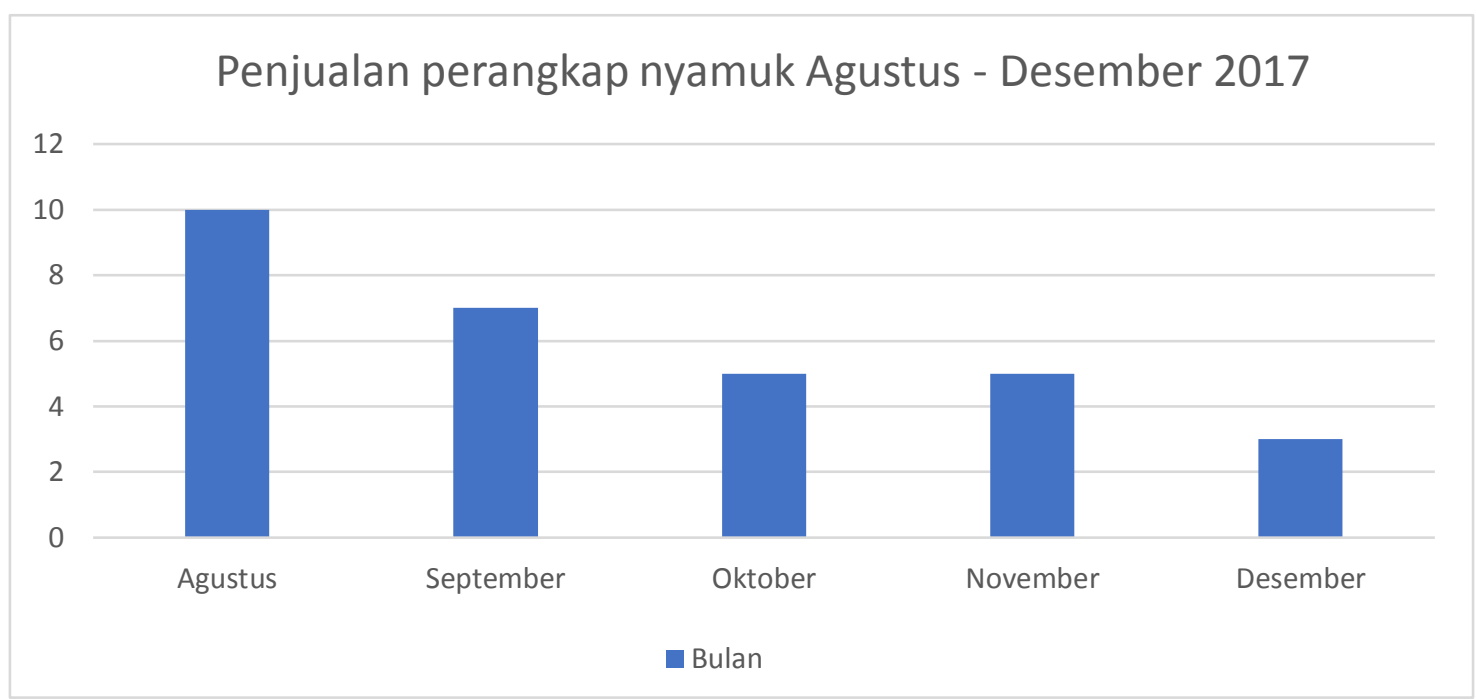

Gambar 2. Penjualan Perangkap Nyamuk ZZ ONE

Sumber : PT Global Indoraya Lestari (2017)

Namun ada salah satu perusahaan elektronik PT Global Indoraya Lestari di Indonesia tepatnya di Jakarta ini yang menawarkan suatu produk-produk elektronik berupa alat-alat perangkap nyamuk yang memang jenis produk seperti ini sudah banyak pesaingnya dari berbagai merek lainnya seperti merek krisbow, idealife, dan lain-lain. Namun perusahaan PT Global Indoraya Lestari masih mempunyai beberapa kelemahan didalamnya yaitu Brand equity dan Perceived product quality yang masih kurang serta kurangnya penyampaian nilai-nilai yang didapatkan dari produk Customer value yang ditawarkan kepada konsumen sehinnga membuat konsumen belum memiliki suatu nilai tambah bagi produk yang ditawarkan dan belum bisa membuat konsumen merasa yakin dengan kualitas dan nilai-nilai yang ditawarkan perusahaan sehingga dapat mempengaruhi Purchase intention dari konsumen.

Untuk mendukung data pernyataan pada gambar 1.5 di atas maka penulis menambahkan sebuah data dari perusahaan yang menunjukkan adanya penurunan penjualan terhadap produk yang ditawarkan oleh perusahaan PT Global Indoraya Lestari tersebut. Dapat dilihat pada bulan Agustus 2017 perusahaan PT Global Indoraya Lestari masih dapat menjual sebanyak 10 unit perangkap nyamuk, bulan September 2017 sebanyak 7 unit perangkap nyamuk, bulan Oktober 2017 sebanyak 5 unit perangkap nyamuk, bulan November sebanyak 5 unit dan terlihat penjualan sangat menurun di bulan Desember 2017 perusahaan hanya menjual perangkap nyamuk sebanyak 3 unit saja dimana dapat dikatakan terlihat penurunan yang cukup signifikan dari bulan ke bulan yang dapat disimpulkan bahwa adanya indikasi masalah Purchase intention didalam perusahaan tersebut sehingga terjadi sebuah penurunan penjualan. 


\section{LANDASAN TEORI}

\section{Brand Equity}

Brand equity (ekuitas merek) merupakan daya Tarik yang ditambahkan kepada pelanggan yang berupa penghargaan kepada sebuah merek produk atau jasa. Nilai sebuah nama merek yang ditambahkan pada suatu produk merupakan gambaran dari ekuitas merek (Killa,2008). Ekuitas merek berbasis pelang-gan(customer-based brand equity)adalahpengaruh diferensialyang dimilikipe-ngetahuan merek atas respon konsumen terhadap pemasaran merek tersebut. Kotler dan Keller (2009)

\section{Perceived Quality}

Perceived Quality merupakan penilaian global berdasarka persepsi pelangan atas apa inti dari kualitas produk dan seberapa baiknya penilaian terhadap merk. Akan lebih sulit untuk mencapai pada level satisfaction dari perceived quality bila perusahaan melakukan perbaikan dan penambahan fitur-fitur baru pada produk secara terus menerus, karena hal itu membuat ekspektasi pelanggan akan naik terhadap kualitas produk (Keller, 2003)

\section{Customer value}

Customer value adalah selisih antara evaluasi calon pelanggan atas semua manfaat serta semua biaya tawaran tertentu dan alternatif-alternatif lain yang dipikirkan (Kotler (2005). Definisi yang diungkapkan Kotler menunjukan bahwa customer value menyangkut manfaat dan pengorbanan, di mana pelanggan akan membandingkan perolehan dari manfaat dan pengorbanan yang dilakukan. Apabila manfaat yang dirasakan lebih besar dari pengorbanan maka kemungkinan besar ia akan memilih nilai tawaran tersebut, dan begitu pun sebaliknya apabila manfaat yang dirasakan lebih sedikit dari pengorbanan yang dilakukan maka pelanggan tersebut akan meninggalkan tawaran perusahaan

\section{METODOLOGI PENELITIAN}

Pada penelitian ini peneliti menggunakan jenis penelitian asosiatif. Penelitian asosiatif merupakan dugaan tentang ada hubungan antar variabel dalam populasi yang akan diuji melalui hubungan antar variabel dalam sampel yang diambil dari populasi tersebut (Sugiyono, 2015 ). Untuk itu dalam langkah awal pembuktiannya, maka perlu dihitung terlebih dahulu koefisien korelasi antar variabel dalam sampel, baru koefisien yang ditemukan itu diuji signifikasinya.

Penelitian ini dilakukan untuk mengetahui pengaruh variabel independen terhadap variabel dependen, yaitu variabel Brand equity (X1) dan Perceived product quality (X2) terhadap Customer value (Y) yang memiliki dampak kepada Purchase intention (Z) pada PT Global Indoraya Lestari dan time horizon yang digunakan adalah cross-sectional, yang dilakukan dengan hanya satu waktu dan hanya satu kali saja untuk menjawab pertanyaan yang diberikan oleh peneliti untuk mencari hubungan antara variabel independen dan variabel dependent.

Jenis data yang digunakan dalam penelitian ini adalah kuantitatif. Metode kuantitatif sudah cukup lama digunakan sehingga sudah mentradisi sebagai metode untuk penelitian, 
metode ini sebagai metode ilmiah/scientific karena telah memenuhi kaidah-kaidah ilmiah yaitu konkrit/empiris, obyektif, terukur, rasional, dan sistematis (Sugiyono, 2016)

Teknik pengambilan sampel yang digunakan oleh peneliti pada penelitian adalah Nonprobability Sampling. Namun metode Nonprobability Sampling yang digunakan peneliti pada penelitian ini adalah Convenience Sampling. Dikatakan Convenience Sampling karena pengambilan anggota sampel dari populasi yang dilakukan peneliti memiliki kebebasan untuk memilih siapa saja yang responden yang ditemui (Sugiyono,2015). Jadi pada penelitian ini peneliti melakukan filterisasi dengan menggunakan pengambilan sampel dengan populasi pada individu yang berdomisili di kota Jakarta dan yang regulary menggunakan obat nyamuk.

\section{HASIL PENELITIAN}

Adapun hasil dalam penelitian analisis pengaruh Brand Equity dan Perceived Product Quality terhadap Customer Value adalah sebagai berikut :

Tabel 1 Path Coefficient

\begin{tabular}{|c|c|c|c|c|c|}
\hline Variabel & $\begin{array}{l}\text { Original } \\
\text { Sample } \\
\text { (O) }\end{array}$ & $\begin{array}{l}\text { Sample } \\
\text { Mean } \\
\text { (M) }\end{array}$ & $\begin{array}{l}\text { Standard } \\
\text { Deviation } \\
\text { (STDEV) }\end{array}$ & $\begin{array}{l}\text { T Statistics } \\
(|\mathrm{O} / \mathrm{STDEV}|)\end{array}$ & P Values \\
\hline $\begin{array}{l}\text { brand equity } \quad \text {-> } \\
\text { customer value_ }\end{array}$ & 0.289 & 0.285 & 0.062 & 4.658 & 0.000 \\
\hline $\begin{array}{l}\text { brand equity }->\text { purchase } \\
\text { intention }\end{array}$ & 0.206 & 0.214 & 0.127 & 1.617 & 0.107 \\
\hline $\begin{array}{l}\text { customer value_ } \quad-> \\
\text { purchase intention }\end{array}$ & 0.060 & 0.050 & 0.137 & 0.440 & 0.660 \\
\hline 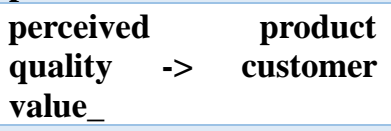 & 0.628 & 0.636 & 0.058 & 10.920 & 0.000 \\
\hline $\begin{array}{l}\text { perceived } \\
\text { quality } \\
\text { intention }\end{array}$ & 0.480 & 0.488 & 0.150 & 3.202 & 0.001 \\
\hline
\end{tabular}

Tabel 2 Specific Indirect Effects

\begin{tabular}{|c|c|c|c|c|c|}
\hline Variabel & $\begin{array}{l}\text { Original } \\
\text { Sample } \\
\text { (O) }\end{array}$ & $\begin{array}{l}\text { Sample } \\
\text { Mean (M) }\end{array}$ & $\begin{array}{l}\text { Standard } \\
\text { Deviation } \\
\text { (STDEV) }\end{array}$ & $\begin{array}{l}\text { T Statistics } \\
(\mid \text { O/STDEV|) }\end{array}$ & $\begin{array}{l}\mathbf{P} \\
\text { Values }\end{array}$ \\
\hline $\begin{array}{lcc}\text { brand } & \text { equity } & -> \\
\text { customer value_ } & -> \\
\text { purchase intention } & \end{array}$ & 0.017 & 0.016 & 0.041 & 0.427 & 0.670 \\
\hline $\begin{array}{llr}\text { perceived } & \text { product } \\
\text { quality } & \text {-> } & \text { customer } \\
\text { value_- }-> & \text { purchase } \\
\text { intention } & & \end{array}$ & 0.038 & 0.031 & 0.087 & 0.435 & 0.664 \\
\hline
\end{tabular}

Berdasarkan data pada tabel dapat disimpulkan bahwa uji hipotesis dari Structural Test Model sebagai berikut: 


\section{Uji hipotesis pengaruh Brand Equity terhadap Customer value}

Berdasarkan pada table 1 terlihat bahwa $\mathrm{T}$ statistic pada variable brand equity bernilai positif sebesar 4,656 lebih besar daripada nilai t table sebesar 1,96 dan sehingga dapat disimpulkan bahwa Ho ditolak dan Ha diterima, dengan kata lain secara parsial brand equity berpengaruh secara signifikan terhadap customer value

\section{Uji Hipotesis pengaruh Perceived product quality terhadap customer value}

Berdasarkan pada table 1 terlihat bahwa $\mathrm{T}$ statistic pada variable perceived product quality bernilai positif sebesar 10,920 lebih besar daripada nilai t table sebesar 1,96 sehingga dapat disimpulkan bahwa Ho ditolak dan Ha diterima, dengan kata lain secara parsial perceived product quality berpengaruh secara signifikan terhadap customer value

\section{Uji Hipotesis pengaruh Brand Equity terhadap Purchase Intention}

Berdasarkan pada table 1 terlihat bahwa T statistic pada variable Brand Equity bernilai positif sebesar 1,617 lebih kecil daripada nilai t table sebesar 1,96 sehingga dapat disimpulkan bahwa Ho diterima dan Ha ditolak, dengan kata lain secara parsial brand equity tidak berpengaruh secara signifikan terhadap purchase intention

\section{Uji hipotesis pengaruh perceived product quality terhadap purchase intention}

Berdasarkan pada table 1 terlihat bahwa $\mathrm{T}$ statistic pada variable perceived product quality bernilai positif sebesar 3,202 lebih besar daripada nilai t table sebesar 1,96 sehingga dapat disimpulkan bahwa Ho ditolak dan Ha diterima, dengan kata lain secara parsial perceived product quality berpengaruh secara signifikan terhadap purchase intention

\section{Uji Hipotesis pengaruh customer value terhadap purchase intention}

Berdasarkan pada table 1 terlihat bahwa T statistic pada variable customer value bernilai positif sebesar 0,440 lebih kecil daripada nilai t table sebesar 1,96 sehingga dapat disimpulkan bahwa Ho diterima dan Ha ditolak, dengan kata lain secara parsial customer value tidak berpengaruh secara signifikan terhadap purchase intention

\section{Uji Hipotesis pengaruh brand equity melalui customer value terhadap purchase intention}

Berdasarkan pada table 1 terlihat bahwa $\mathrm{T}$ statistic pada variable brand equity bernilai positif sebesar 0,440 lebih kecil daripada nilai t table sebesar 1,96 sehingga dapat disimpulkan bahwa Ho diterima dan Ha ditolak, dengan kata lain secara parsial brand equity tidak berpengaruh secara signifikan terhadap purchase intention

Uji Hipotesis pengaruh perceived product quality melalui customer value terhadap purchase intention

Berdasarkan pada table 1 terlihat bahwa $\mathrm{T}$ statistic pada variable perceived product quality bernilai positif sebesar 0,435 lebih kecil daripada nilai t table sebesar 1,96 sehingga dapat disimpulkan bahwa Ho diterima dan Ha ditolak, dengan kata lain secara parsial perceived product quality tidak berpengaruh secara signifikan terhadap customer value 


\section{KESIMPULAN}

Berdasarkan hasil penelitian ini, yaitu untuk mengetahui apakah terdapat pengaruh pada Brand equity dan Perceived product quality terhadap Customer value yang memiliki dampak terhadap Purchase intention pada produk perangkap nyamuk Zz One. Berikut di bawah ini merupakan kesimpulan berdasarkan hasil analisis data yang telah dilakukan sebelumnya, maka dapat disimpulkan bahwa Brand equity memiliki pengaruh yang signifikan terhadap Customer value, apabila terbentuk Brand equity yang positif maka dapat memicu naiknya Customer value pada produk perangkap nyamuk $\mathrm{Zz}$ One.Perceived product quality memiliki pengaruh yang signifikan terhadap Customer value, apabila terbentuk Perceived product quality yang positif maka dapat memicu naiknya Customer value pada produk perangkap nyamuk $\mathrm{Zz}$ One.Brand equity tidak memiliki pengaruh yang signifikan terhadap Purchase intention, apabila terbentuk Brand equity yang positif maka perlu ditingkatkan agar dapat memicu naiknya Purchase intention pada produk perangkap nyamuk $\mathrm{Zz}$ One.Perceived product quality memiliki pengaruh yang signifikan terhadap Purchase intention, apabila terbentuk Perceived product quality yang positif perlu ditingkatkan agar dapat memicu naiknya Purchase intention pada produk perangkap nyamuk $\mathrm{Zz}$ One.Customer value tidak memiliki pengaruh yang signifikan terhadap Purchase intention, apabila terbentuk Customer value yang positif maka perlu ditingkatkan agar dapat memicu naiknya Purchase intention pada perangkap nyamuk $\mathrm{Zz}$ One.Brand equity melalui Customer value tidak memiliki pengaruh yang signifikan pada Purchase intention. Sehingga dapat disimpulkan bahwa keduanya Brand equity melalui Customer value tidak dapat mempengaruhi Purchase intention pada perangkap nyamuk $\mathrm{Zz}$ One.Perceived product quality dan Customer value tidak memiliki pengaruh yang signifikan pada Purchase intention. Sehingga dapat disimpulkan bahwa keduanya Perceived product quality melalui Customer value tidak dapat mempengaruhi Purchase intention pada perangkap nyamuk $\mathrm{Zz}$ One.

\section{DAFTAR PUSTAKA}

Abdillah, W. (2018). In Metode Penelitian Terpadu Sistem Informasi - Pemodelan Teoretis, Pengukuran, dan Pengujian Statistis. Jakarta: PENERBIT ANDI.

Ghozali, I., \& Latan, H. (2015). In Konsep, Teknik dan Aplikasi Menggunakan Program SmartPLS 3.0 Untuk Penelitian Empiris (2nd). Semarang: Badan Penerbit Universitas Diponegoro.

Hakim, L., Susanti, N., \& Ujianto. (2017). Influence of Customer Relationship Management, Brand Equity, Perceived Product Quality, Perceived Price on Customer Value and Purchase Intention . 
http://industri.bisnis.com. (2017). Bayer Indonesia Perkuat Pasar Pengendali Hama. Retrieved from http://industri.bisnis.com/read/20171018/257/700790/bayer-indonesiaperkuat-pasar-pengendali-hama

Keller, K. L. (2013). Strategic Brand Management. England: Pearson Education Limited.

Kotler , P., \& Amstrong, G. (2016). Principles of Marketing. United States: Pearson Education Limited.

Kotler, P., \& Keller, K. L. (2016). A FRAMEWORK FOR MARKETING MANAGEMENT. England: Pearson Education Limited .

Kotler, P., \& Kevin , L. K. (2012). Marketing Management. New York: Prentice Hall.

Kotler, P., Keller, K. L., Brady, M., Goodman, M., \& Hansen, T. (2009). Marketing Management. England: Pearson Education Limited.

Schiffman , L., \& Wisenblit, J. (2015). Consumer Behavior. England: Pearson Education Limited.

Sekaran , U., \& Bougie, R. (2016). Research Methods for Business. United Kingdom: Designs and Patents Act 1988.

Siahaan, M., Pangemanan, S., \& Pandowo, M. (2014). Price, Brand Equity, and Perceived Quality on Purchase Intention of Honda Scooter Motorcylce in Manado.

Sudarsono, S., \& Kurniawati, D. (2013). Elemen Ekuitas Merek Dalam Keputusan Pembelian Laptop.

Sugiarto, B. U., \& Subagio, H. (2014). ANALISA PENGARUH PRODUK, KUALITAS PELAYANAN, HARGA, DAN STORE ATMOSPHERE TERHADAP MINAT BELI DI DREAM OF KHAYANGAN ART RESTO SURABAYA.

Sugiyono. (2015). STATISTIKA UNTUK PENELITIAN. Bandung: ALFABETA.

Sugiyono. (2016). Metode Penelitian. Bandung: ALFABETA.

Tarmedi, E., \& Asri, P. (2009). PENGARUH PERCEIVED QUALITY DARI BRAND EQUITY TERHADAP KEPUTUSAN PEMBELIAN DETERJEN BUKRIM.

Tasci, A. (2016). A critical review of consumer value and its complex relationships in the consumer-based brand equity network.

Tharmi, U., \& Senthilnathan, S. (2017). The Relationship of Brand Equity to Purchase Intention

Valdo, J., \& Subagio, H. (2017). Analisa Pengaruh Brand Equity terhadap Purchase Intention Konsumen pada Produk PC tablet Apple Ipad di Surabaya. 